\title{
Patterns of Injuries in Fatal Fall from Height Cases in Gharbia Governorate: Autopsy Study
}

\author{
Amira F. Ramadan'; Eman M. Soliman²; Mona M. Abo El-Noor²; Marwa M. Shahin ${ }^{2 *}$
}

1 Tanta Department of Forensic Institute, Gharbia Governorate, Egypt

2 Forensic Medicine and Clinical Toxicology Department, Faculty of Medicine, Tanta University

*Corresponding author: Marwa M. Shahin

marwa.shahin@med.tanta.edu.eg

Mob. 00201222836827

00201069768108

\section{ABSTRACT}

Background: A fall is defined as an event in which a person inadvertently lands on the ground after falling from a higher place. It is the second most common cause of unintentional injury associated mortality after traffic accidents. Sometimes, when a body is brought for autopsy, it is unclear whether injuries are due to a fall from a height or due to blunt trauma from other causes. Objectives: This study aims to spotlight injuries in fatal falls from a height so that any pattern that might help discriminate between these injuries and injuries due to blunt trauma from other causes could be identified. Methods: This work included a retrospective study of fatal fall from height cases subjected to medico-legal autopsy in Tanta Department of Forensic Institute- Gharbia Governorate during the start of January 2012 at the end of October 2015. A cross-sectional study with autopsy was carried out on a fatal fall from height cases from the start of November 2015 to the end of October 2016. Results: The majority of cases (52.38\%) were in the age group 20-40 years. Males registered $76.2 \%$ of cases. Urban areas recorded $64.3 \%$ of cases. The Head first impact was noticed in $66.7 \%$ of cases. Poly-trauma was the cause of death in $76.2 \%$ of cases. Nearly all cases showed diffuse head injuries involving bones, meninges, and brain and accompanying intracranial hemorrhage. The majority of cases registered negative drug screening. Conclusion: External injuries, including abrasions, contusions, and lacerations, were diffusely involving different body regions except for the neck. Skull fractures are distributed evenly amongst vault and base. Polytrauma is the most predominant cause of death. After the brain, thoracic cage and lung injuries were encountered in more than half of the cases. The liver is the most common abdomino-pelvic organ involved.

KEYWORDS: Fall from height, polytrauma, first impact, Forensic Institute, head injuries.

\section{INTRODUCTION}

A fall is an event in which a person inadvertently lands on the ground from a higher place, such as a building, roof, ladder, or any other elevated area in a workplace (Mirza et al., 2013 and Kasim et al., 2018). In 2012, WHO categorized falls as the second highly common cause of unintentional mortality caused by injury after traffic accidents.
They constitute a significant percentage of admissions of blunt trauma cases in the emergency department (Ersoy et al., 2014). The rapid vertical deceleration injuries of falling from height exemplify a unique form of blunt trauma. The characteristics of injuries depend on several factors; the height of falling, the composition of the impact surface, the landing position of the body, as well as individual factors such as age, sex, 
body weight, and comorbidities of the patient (Gill, 2001; Lapostolle et al., 2005; Petaros et al., 2013; Bruno et al., 2014).

Several risk factors are involved in mortality and morbidity of falls. They could be categorized into intrinsic and extrinsic factors. Gender, muscular weakness, balance and gait impairment, sensory deficits, chronic diseases, depression, cognitive impairment, and age more than 80 years constitute intrinsic risk factors. Among extrinsic risk factors, drug abuse, alcohol overuse, and ignorance of safety principles are the most important (Jamebozorgi et al., 2013).

Forensic reconstruction of fatal falls from heights represents a challenging task (Thierauf A et al., 2010). Falling could be accidental, on purpose (suicide attempt or homicide), or due to psychiatric illness and misuse of drugs (Osifo et al., 2010). In forensic practice, combined injury patterns and many possibilities of case scenarios render the differentiation between accidental and intentional settings difficult, particularly in the absence of a reliable eye witness, suicidal notes, or other indications suggesting suicide or homicide (Holger Muggenthaler et al., 2013 and Mirza et al., 2013).

Falls from heights are considered one of the dilemmas in forensic case works. Postmortem findings have to be evaluated within the framework of the victim's medical, social, and psychiatric history and findings at the death scene and toxicology results to reach the clearest possible picture of death's circumstances (Ramadan et al., 2016).

Over the years, several studies have been carried out to evaluate injuries induced by falls from heights (Goonetilleke, 1980; Gupta et al., 1982; Reiber, 1993; Li and Smialek, 1994). However, scanty studies exclusively discussed typical patterns of injuries in adults after falling from buildings (Prathapan and Umadethan, 2015).
Sometimes, when a body is subjected to an autopsy, it is unclear whether injuries are caused by a fall from a height or due to blunt trauma from other causes (Kohli and Banerjee, 2006).

Henceforth, this study aimed to spotlight injuries caused by fatal falls from a height so that any pattern that might help differentiate between these injuries and injuries caused by blunt trauma from other causes could be identified.

\section{SUBJECTS AND METHODS}

1-Place of the study and choice of cases: This work included a retrospective study of fatal fall from height cases subjected to medico-legal autopsy in Tanta Department of Forensic Institute during the period from the start of January 2012 to the end of October 2015. Also, a cross-sectional study was carried out on a fatal fall from height cases that were subjected to medico-legal autopsy in Tanta Department of Forensic Institute from the start of November 2015 to the end of October 2016.

Eligibility criteria: The study included all fatal fall cases from height during the period between the start of January 2012 to the end of October 2016, which was subjected to medico-legal autopsy in Tanta Department of Forensic Institute. Cases with the evident cause of death other than fall from a height, together with putrefied cases, were excluded.

Ethical consideration: This study was conducted after approval of Tanta Department of Forensic Institute, Gharbia Governorate, Egypt, and the institutional research ethics committee, Faculty of Medicine, Tanta University. A code number was used for each participant with 
anonymous data analysis to secure confidentiality.

\section{2- Methods}

- Retrospective study: Data about age, gender, residence, medical history, the height of fall, pattern of injuries, and cause of death were collected. Results of toxicological screening and histopathological examination were also obtained from files of fatal fall from height cases.

- Cross-section study: Information concerning the scene of fall, past medical and psychiatric history, and circumstances surrounding the death were obtained from prosecution notes and police reports. For every case, age, gender, residence, past medical history, and circumstances surrounding the fall were recorded. Clothes were examined very carefully for any tears, stains, body fluid, and any other contaminants. A thorough external examination was carried out, and the postmortem changes were recorded. All detected external injuries were documented.

During the autopsy, the Luttele method (Prathapan and Umadethan, 2015) was adopted for internal examination. Different patterns of injuries of all body regions were reported. Blood and urine samples, liver tissue, kidney tissue, and stomach contents were examined for toxicological screening, and the results were reported. Fatal falls from height with no gross injuries, tissue samples for histopathological examination were taken, and the results were reported.
3- Statistical analysis: All statistical analyses were done using SPSS v20.Qualitative data were represented as numbers and percentages in brackets. Chi-square goodness of fit test was used to determine whether sample data are consistent with a hypothesized equal distribution between categories while and Fisher's Exact test was used to examine associations between two variables. Significance at $\mathrm{p}<0.05$ was adopted for the interpretation of test results (Knapp, 2017).

\section{RESULTS}

The present study was carried out on 42 cases of fatal fall from height in Gharbia Governorate. The majority of cases $(52.38 \%)$ were in the age group 20-40 years and $21.43 \%$ of cases in 40-60 years. More than 60 years represented $14.29 \%$, and 1-20 years accounted for $11.90 \%$, with a statistically significant difference between age groups. Males registered $76.2 \%$ of cases with statistically significant gender differences (Table 1).

Urban and rural areas recorded $64.3 \%$ and $35.7 \%$, respectively. Cases were distributed throughout the year with no seasonal statistical significance. Four cases had a history of psychic problems. On the other hand, no case had a history of drug abuse.

Table (2) shows a statistically significant difference in place of fall; $78.57 \%$ of cases occurred at home, $14.28 \%$ at the workplace, $2.38 \%$ at the hospital, $2.38 \%$ at the road, and $2.38 \%$ of cases the place of fall was not obtained. Accidental falls occurred in $66.7 \%$ (statistically significant), while $4.8 \%$ of cases were homicidal. Both suicidal, intended for escape, and obscure falls registered $9.5 \%$ each. The Head first impact (statistically significant) was noticed in $66.7 \%$ of cases, feet first impact, and side first impact recorded equal distribution of 
$16.7 \%$ for each. Poly-trauma was the cause of death in $76.2 \%$ of cases (statistically significant), $19.0 \%$ died due to head injuries, $2.4 \%$ due to chest injuries, and $2.4 \%$ due to abdomen injuries. There were multiple gross fatal injuries in all the studied cases, except for two (4.8\%) cases.

Height of fall was not obtained in $7.1 \%$ of cases, $78.6 \%$ fall from a height more than 20 feet, and $23.8 \%$ fall from a height less than 20 feet. No statistical association could be detected between the cause of death and the height of the fall $(P<0.68)$.

Histopathological examination of the brain showed diffuse axonal damage. The majority of cases registered negative drug screening. Only $2.4 \%$ of cases were positive for psychotropic drug screening.

Feet were the primary impact in $75 \%$ of intended jump cases. At the same time, head first impact appeared in $100 \%$ of homicidal cases, $71.4 \%$ of accidental cases, $50 \%$ of suicidal cases, and $75 \%$ of obscure manner cases. However, no significant association could be detected between the manner of death and the site of direct impact $\left(\mathrm{X}^{2}=10.9\right.$,
$\mathrm{P}=.095)$. A significant statistical association could be perceived between polytrauma as the cause of death and the head as a direct impact (Table 3).

Fig. (1) showed that external injuries, including abrasions, contusions, and lacerations, were diffusely involving different body regions. External injuries involving the neck region were only seen in 1 case out of 42 .

Nearly all cases showed diffuse head injuries involving bones, meninges, and brain and accompanying intracranial hemorrhage. Only 1 case had a cervical vertebral fracture. Fracture ankle and rest were present in only 5 cases. Upper and lower limb injuries were seen in 26.2\% of cases, as noticed in Fig. (2).

The autopsy revealed that thoracic cage and lung injuries were encountered in more than half of the cases. Two cases had cardiac injuries, and one case had thoracic vertebrae injury. The liver was the most commonly injured abdominopelvic organs, as declared in Fig. (3).

Fig. 4, 5, 6, 7, and 8 reveal some injuries registered during the autopsy.

\section{Tables}

Table (1): Age and sex distribution of the studied cases ( $\mathrm{N}=42)$

\begin{tabular}{|c|c|c|c|c|c|c|c|c|c|}
\hline & \multicolumn{6}{|c|}{ Sex } & \multicolumn{2}{|c|}{$\begin{array}{l}\text { Chi Square goodness of } \\
\text { fit test }\end{array}$} \\
\hline & & \multicolumn{2}{|c|}{ Male } & \multicolumn{2}{|c|}{ Female } & \multicolumn{2}{|c|}{ Total } & $\mathbf{X}^{2}$ & P value \\
\hline & & $\mathbf{N}$ & $\%$ & $\mathbf{N}$ & $\%$ & $\mathbf{N}$ & $\%$ & \multirow{6}{*}{17.619} & \multirow{6}{*}{$.001 *$} \\
\hline \multirow{5}{*}{ Age } & $1-<20$ & 2 & 40 & 3 & 60 & 5 & 11.90 & & \\
\hline & $20-<40$ & 17 & 77.3 & 5 & 22.7 & 22 & 52.38 & & \\
\hline & $40-<60$ & 7 & 77.8 & 2 & 22.2 & 9 & 21.43 & & \\
\hline & $>60$ & 6 & 100.0 & 0 & 0 & 6 & 14.29 & & \\
\hline & Total & 32 & 76.2 & 10 & 23.8 & \multirow{3}{*}{\multicolumn{2}{|c|}{100}} & & \\
\hline \multirow{2}{*}{$\begin{array}{|lr|}\text { Chi } & \text { Square } \\
\text { goodness of fit }\end{array}$} & $\mathrm{X}^{2}$ & \multicolumn{4}{|c|}{11.524} & & & & \\
\hline & P value & \multicolumn{4}{|c|}{$.001 *$} & & & & \\
\hline
\end{tabular}

*Significance at $\mathbf{p}<0.05$ 
Table (2): Scene of fall and results of the autopsy in the studied cases $(\mathrm{N}=42)$

*Significance at $\mathbf{p}<\mathbf{0 . 0 5}$

\begin{tabular}{|c|c|c|c|c|c|}
\hline & & & & \multicolumn{2}{|c|}{ Chi Square goodness of fit test } \\
\hline & & $\mathrm{N}$ & $\%$ & $\mathbf{X}^{2}$ & P value \\
\hline \multirow{5}{*}{ Place of fall } & Home & 33 & 78.57 & \multirow{5}{*}{92.28} & \multirow{5}{*}{$<.001 *$} \\
\hline & At work place & 6 & 14.28 & & \\
\hline & Hospital & 1 & 2.38 & & \\
\hline & Road & 1 & 2.38 & & \\
\hline & not mentioned & 1 & 2.38 & & \\
\hline \multirow{3}{*}{ Site of first impact } & Head & 28 & 66.7 & \multirow{3}{*}{21.0} & \multirow{3}{*}{$<.001 *$} \\
\hline & Feet & 7 & 16.7 & & \\
\hline & Side & 7 & 16.7 & & \\
\hline \multirow{5}{*}{ Manner of death } & Accidental & 28 & 66.7 & \multirow{5}{*}{57.524} & \multirow{5}{*}{$<.001^{*}$} \\
\hline & Homicidal & 2 & 4.8 & & \\
\hline & Suicidal & 4 & 9.5 & & \\
\hline & intended jump & 4 & 9.5 & & \\
\hline & Obscure & 4 & 9.5 & & \\
\hline \multirow{4}{*}{ Cause of death } & Polytrauma & 32 & 76.2 & \multirow{4}{*}{61.81} & \multirow{4}{*}{$<.001 *$} \\
\hline & head only & 8 & 19 & & \\
\hline & chest only & 1 & 2.4 & & \\
\hline & abdomen only & 1 & 2.4 & & \\
\hline
\end{tabular}

Table (3): Association between the manner of death, the cause of death and the site of primary impact $(\mathrm{N}=42)$

\begin{tabular}{|c|c|c|c|c|c|c|c|c|}
\hline & \multicolumn{4}{|c|}{ Site of primary impact } & \multicolumn{2}{|c|}{ Fisher's Exact test } \\
\hline & & & Head & Feet & Side & Total & $\mathbf{X}^{2}$ & P value \\
\hline \multirow{12}{*}{$\begin{array}{l}\text { Manner of } \\
\text { death }\end{array}$} & \multirow{2}{*}{ Accidental } & $\mathbf{N}$ & 20 & 2 & 6 & 28 & \multirow{10}{*}{10.9} & \multirow{10}{*}{.095} \\
\hline & & $\%$ & 71.4 & 7.1 & 21.4 & 100 & & \\
\hline & \multirow{2}{*}{ Suicidal } & $\mathbf{N}$ & 2 & 1 & 1 & 4 & & \\
\hline & & $\%$ & 50 & 25 & 25 & 100 & & \\
\hline & \multirow{2}{*}{ Homicidal } & $\mathbf{N}$ & 2 & 0 & 0 & 2 & & \\
\hline & & $\%$ & 100 & 0 & 0 & 100 & & \\
\hline & \multirow{2}{*}{$\begin{array}{l}\text { Intended } \\
\text { Jump }\end{array}$} & $\mathbf{N}$ & 1 & 3 & 0 & 4 & & \\
\hline & & $\%$ & 25 & 75 & 0 & 100 & & \\
\hline & \multirow{2}{*}{ Obscure } & $\mathbf{N}$ & 3 & 1 & 0 & 4 & & \\
\hline & & $\%$ & 75 & 25 & 0 & 100 & & \\
\hline & \multirow{2}{*}{ Total } & $\mathbf{N}$ & 28 & 7 & 7 & 42 & & \\
\hline & & $\%$ & 66.7 & 16.7 & 16.7 & 100 & & \\
\hline \multirow{10}{*}{ Cause of death } & \multirow{2}{*}{ Polytrauma } & $\mathbf{N}$ & 20 & 5 & 7 & 32 & \multirow{8}{*}{11.17} & \multirow{8}{*}{$0.032 *$} \\
\hline & & $\%$ & 71.4 & 71.4 & 100 & 76.2 & & \\
\hline & \multirow{2}{*}{ head only } & $\mathbf{N}$ & 8 & 0 & 0 & 8 & & \\
\hline & & $\%$ & 28.6 & 0.0 & 0.0 & 19.0 & & \\
\hline & \multirow{2}{*}{ chest only } & $\mathbf{N}$ & 0 & 1 & 0 & 1 & & \\
\hline & & $\%$ & 0.0 & 14.3 & 0.0 & 2.4 & & \\
\hline & \multirow{2}{*}{ abdomen only } & $\mathbf{N}$ & 0 & 1 & 0 & 1 & & \\
\hline & & $\%$ & 0.0 & 14.3 & 0.0 & 2.4 & & \\
\hline & \multirow{2}{*}{ Total } & $\mathbf{N}$ & 28 & 7 & 7 & 42 & & \\
\hline & & $\%$ & 100.0 & 100.0 & 100.0 & 100.0 & & \\
\hline
\end{tabular}

*Significance at $\mathbf{p}<0.05$ 


\section{Figures}

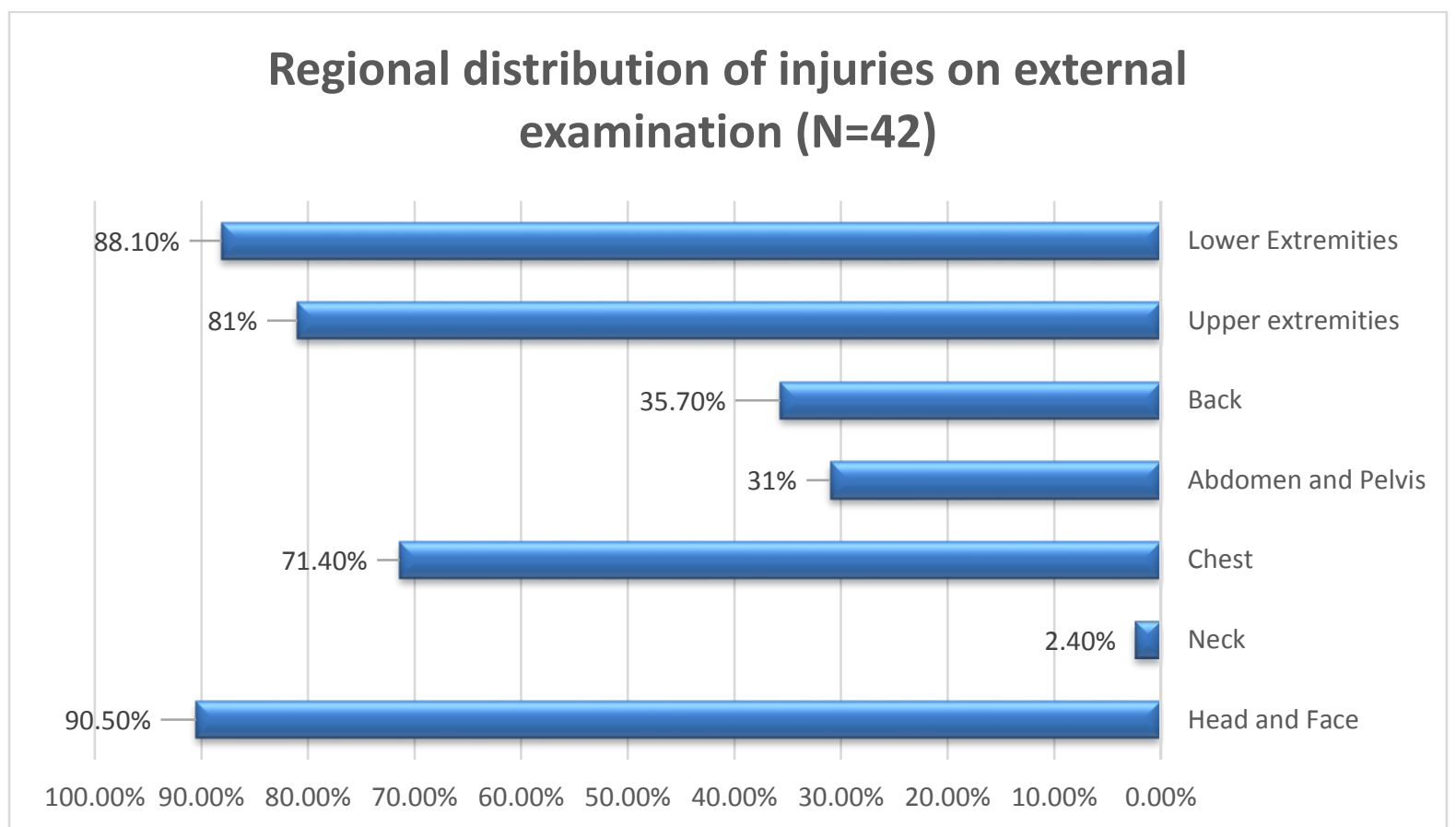

Figure (1): Regional distribution of injuries on external examination $(\mathrm{N}=42)$.

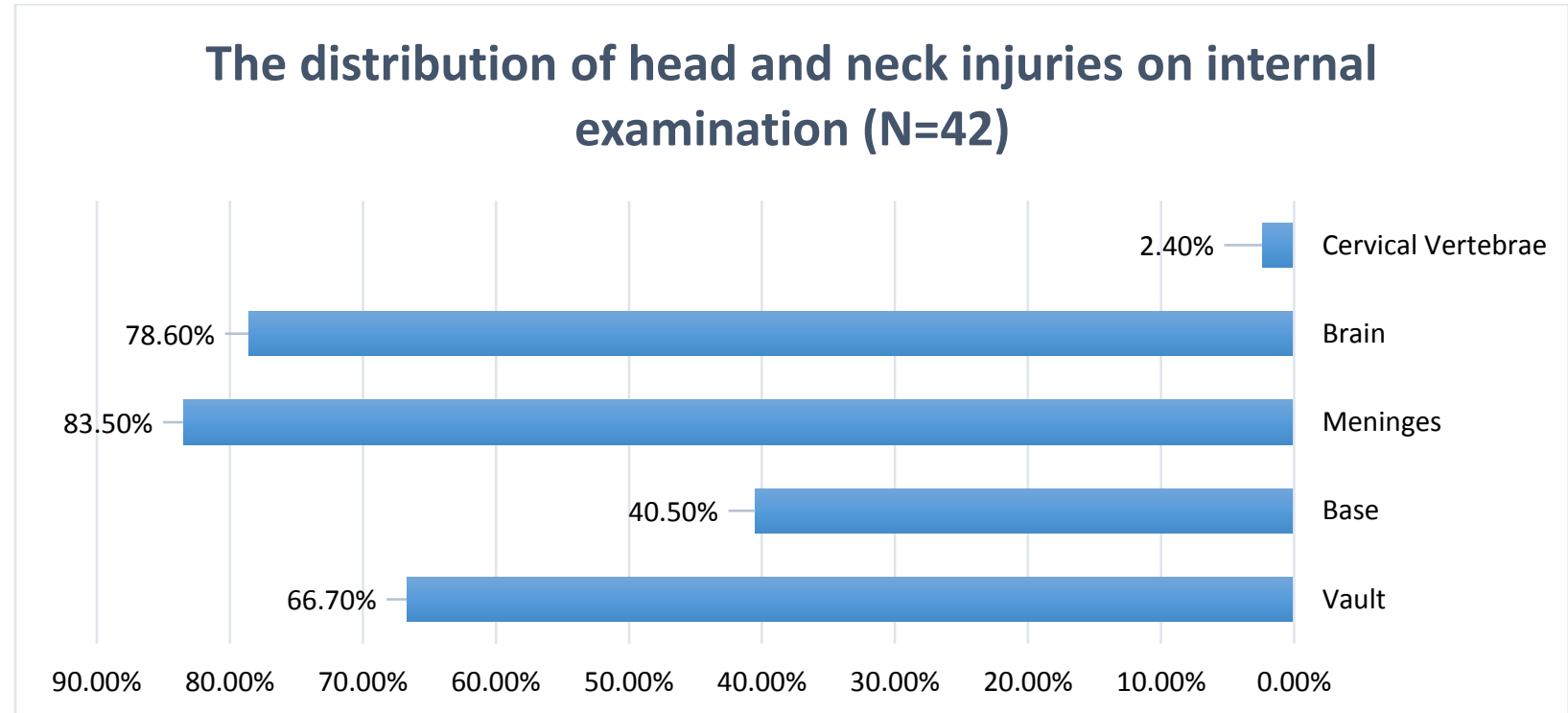

Figure (2): The distribution of head and neck injuries on internal examination (Autopsy) $(\mathbf{N}=\mathbf{4 2})$. 
Percentage of exterimities, thoracic and abdominopelvic Injuries on internal examination ( $N=42)$

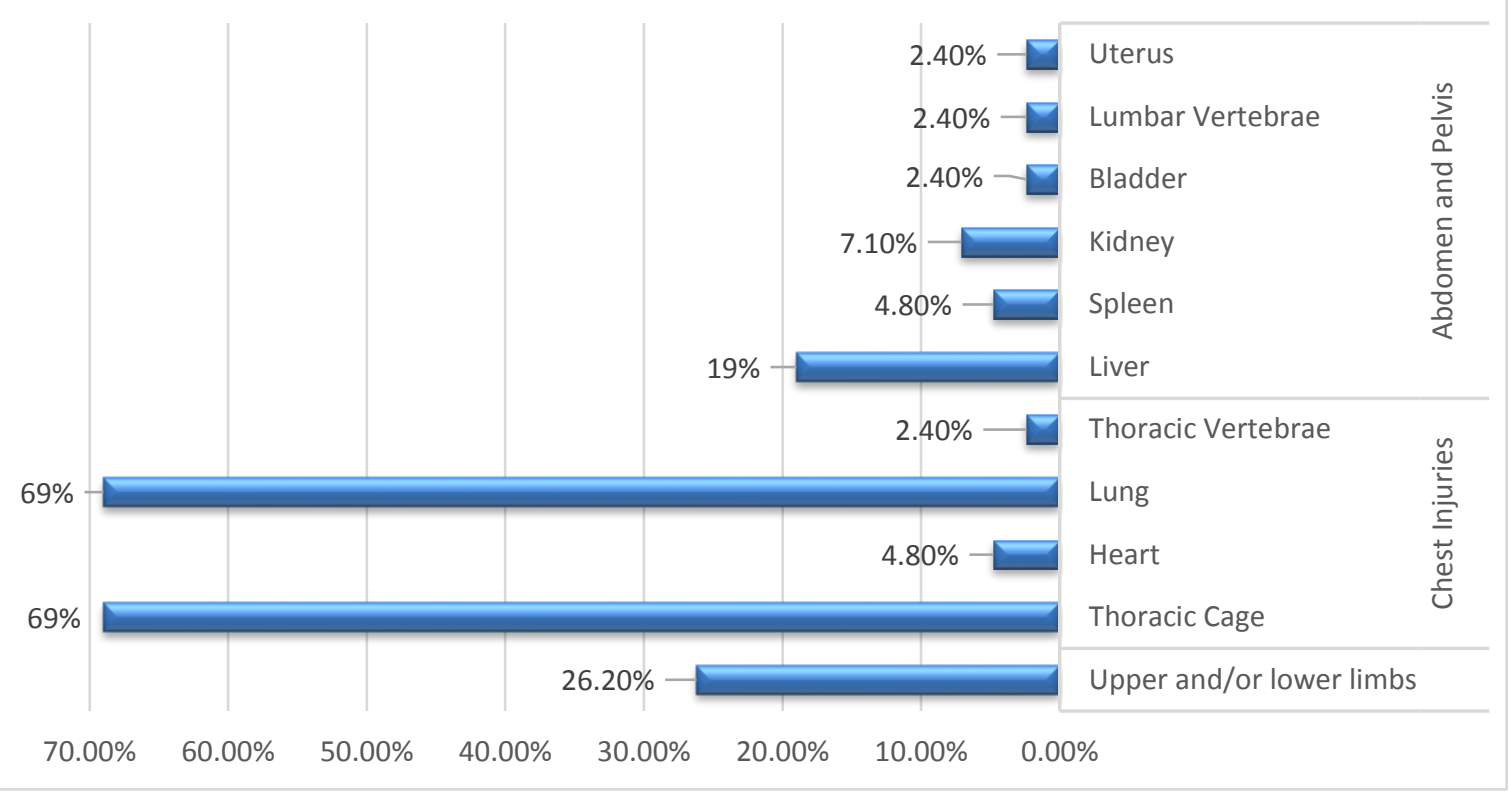

Figure (3): Percentage of exterimities, thoracic and abdomino-pelvic injuries on internal examination (Autopsy) $(\mathrm{N}=42)$.

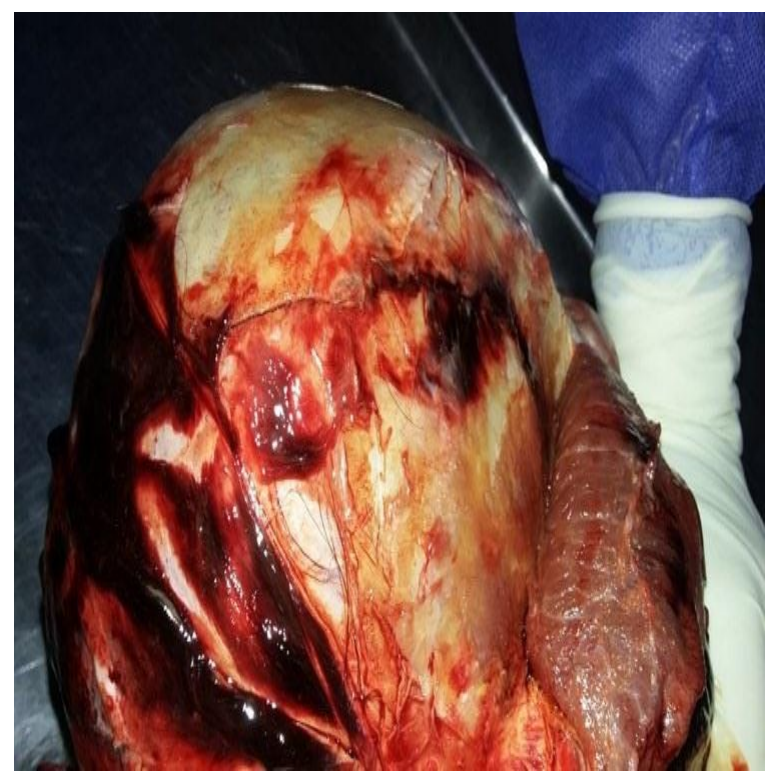

Figure (4): Depressed comminuted fracture with radiating multiple fissure fractures in head first impact.

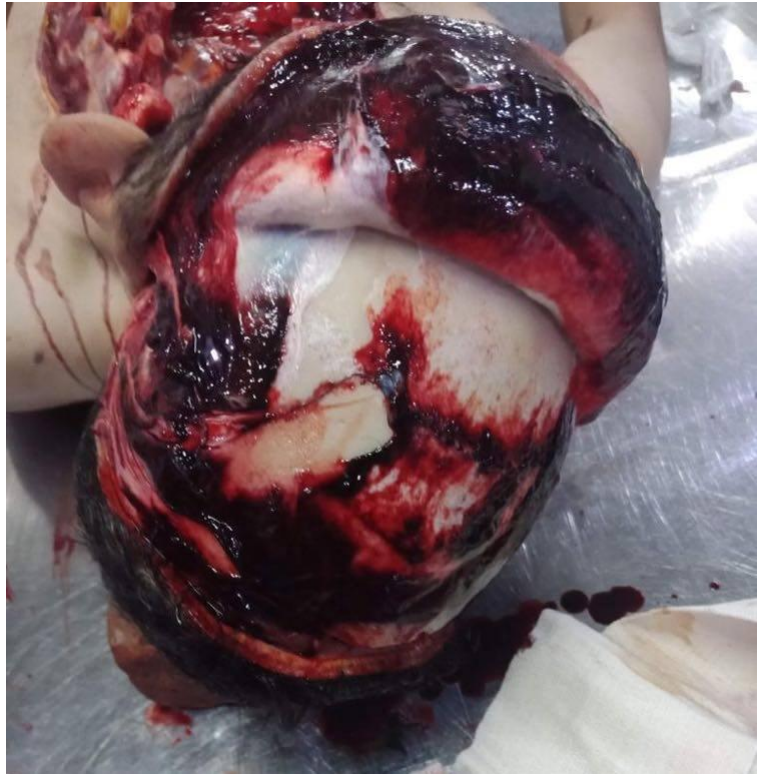

Figure (5): Massive scalp contusions associated with fissure fractures in head first impact. 


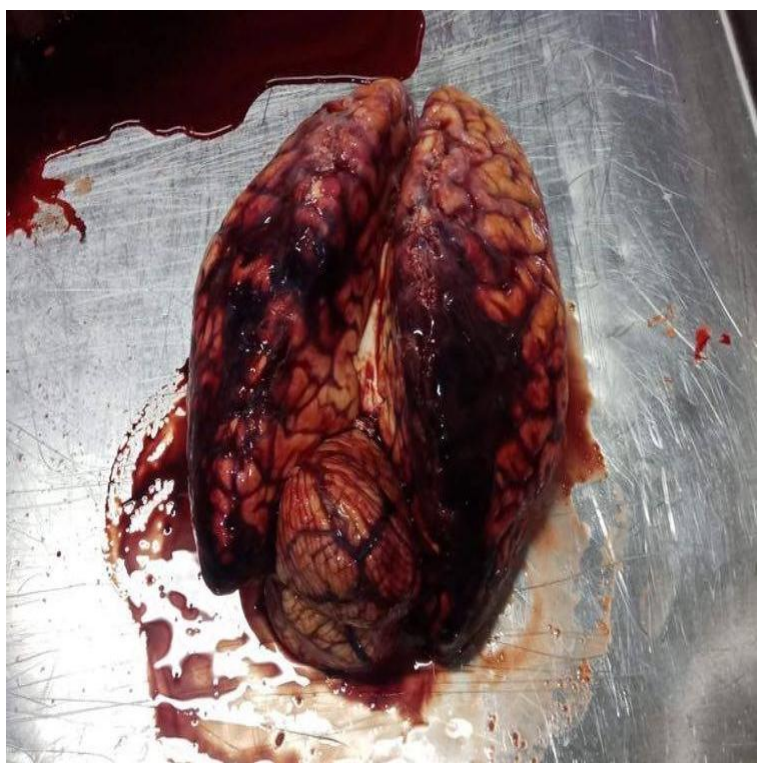

Figure (6): Extensive subdural haemorrhage and brain contusions in head first impact.

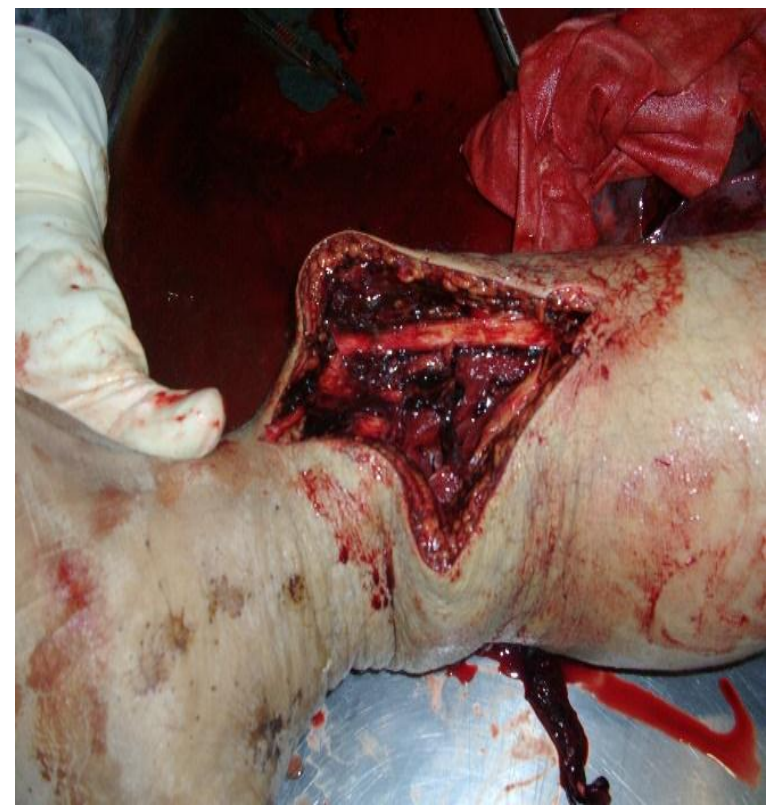

Figure (7): Fracture Tibia and Fibula in Feet first impact.

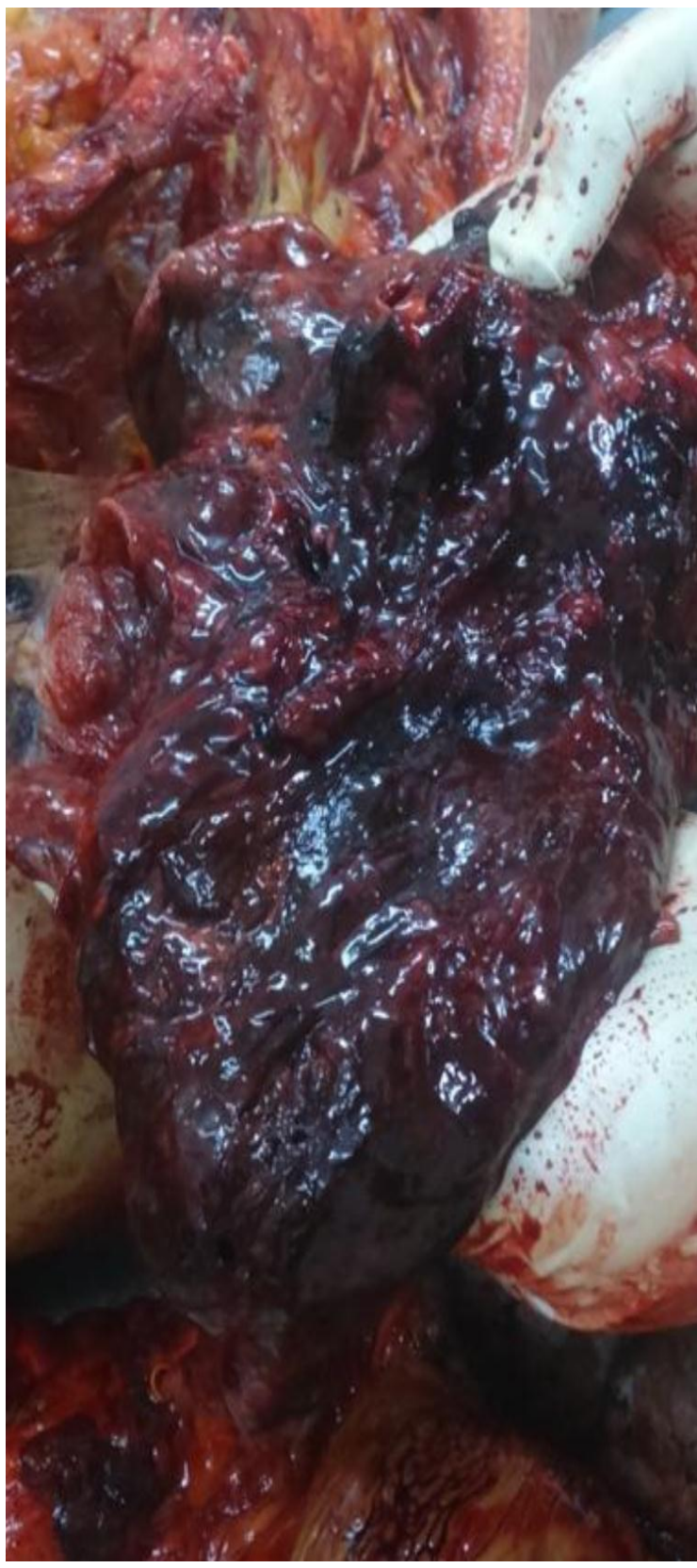

Figure (8): Lung contusions and lacerations in fatal fall from height. 


\section{DISCUSSION}

Falls from a height are the second leading cause of mortality resulted from injury after accidents involving motorized vehicles (Kasim et al., 2018). It has been considered a challenging forensic pathology (Casali et al., 2014). Fatal falls from a height have been topics of numerous medical publications. However, most of these studies have dealt with falls from heights as a whole; including falls from buildings together with stairs, ladders, and even standing height (Goonetilleke, 1980; Reiber, 1993; Li and Smialek, 1994; Hartshorne et al., 1997; Lalwani et al., 1999). The current study was carried out to outline the pattern of injuries caused by fatal falls from a height to discriminate them from injuries resulting from blunt trauma due to other causes.

The current study results revealed a significant increase in fatal falls from height in the age group of $20-40$ years. A result comes in line with previous comparative studies outside and inside Egypt (Osifo et al., 2010; Murthy et al., 2012; EIGohary et al., 2016; Haggag et al., 2016; Ramadan et al., 2016). Nevertheless, Petaros et al. (2013) and Icer et al. (2013) registered different peak ages of 55 years and group between 415 years, respectively. Probably due to the broad age range (1 month to 95 years) involved in their studies. Overall, people in the ages of activity are more prone to trauma. The elderly, especially those over 60 years old, have trouble maintaining balance, which causes more falls (Kasim et al., 2018).

Generally, males in the middle age are more exposed to trauma and accidental falls from a height than females (Haggag et al., 2016; Kasim et al., 2018). This could be explained because males are more exposed to stress or strain than females (EIGohary et al., 2016). They are more exposed to occupational hazards, as they are mostly laborers working in construction, maintenance, and many jobs that carry a risk of falling from a height, especially without proper training or equipment (Ramadan et al., 2016). Based on these facts, a significant increase in the male ratio in this study becomes predictable. Virtual readings with similar results were recorded all over the world through different authors (Murthy et al., 2012; Icer et al., 2013; Jain et al., 2014; Grivna et al., 2014; Haggag et al., 2016; Ramadan et al., 2016).

Comparable to results obtained by Gulati et al., 2012; a significant increase in falling cases that occurred at home was documented in this study. Many falls occurred from rooftops between midnight and dawn. These could be trying to urinate late at night or in the early morning in a state of least attention. Moreover, it could be attributed to low income, where people cannot afford cemented staircases so, they use wooden ladders instead that are often weak and unbalanced, leading to falls. Hence, households need to be safe enough according to regulations (Goren et al., 2003; Kohli and Banerjee, 2006).

In the present study, most cases fall from a height of more than 20 feet ( 6 meters). This could be explained by the destructive nature of cases of falling from height subjected to autopsy examination. Nearby results were obtained by Murthy et al. (2012) and Ramadan et al. (2016), who concluded that in most of their cases, the height of fall was 21- 40 feet (6-12 meters). They studied fatal cases of falling from height brought to autopsy examination outside and inside Egypt, so the height was near like that included in the present study. Kasim et al. (2018) founded that the mean fall height was $6.79 \pm 9.87$ meters for those who died and $2.51 \pm 3.7$ meters for all patients. Agalar et al. (1999) referred to the height of falls as a significant factor in determining the severity of trauma. This is because a falling body undergoes deceleration at the moment of impact. Injuries resulting from the absorption 
of lost energy; the amount of kinetic energy transferred to the ground react with an equal amount of energy against the body. (Arbes and Berzlanovich, 2014). Goodacre et al. (1999) pronounced that fall height is a poor predictor of significant injury. However, the current study could not comment on the relation between the height of fall and severity of injury because trauma scores were missing in available case records.

Accidental falls registered the highest percentage; homicidal falls occurred in the least percentage. Both suicidal, intended for escape and obscure falls registered equal percentages. This result was consistent with Goren et al. (2003), Kumar and Srivastava (2013), ElGohary et al. (2016), Haggag et al., 2016 and Ramadan et al. (2016). Meanwhile, it was not in agreement with Lapostolle et al. (2005), Törő et al. (2006), and Atanasijevic et al. (2009), who found that suicidal falls were the most prevalent. This discrepancy in results could be attributed to the religion and nature of Egyptians, which prohibit suicide.

In most cases, the headfirst impact was noticed, feet first impact, and side the first impact recorded equal distribution for each present study. These findings are in agreement with Kumar and Srivastava (2013), who concluded that, in fall from a height, the head was commonly the site of primary impact. The primary site of impact offers excellent help in determination (Ramadan et al., 2016). According to Kasim et al. (2018), during falls from height, the morbidity and mortality are influenced by the first body part that hits the ground and the lesions resulting from fall impact.

Feet were the primary impact in $75 \%$ of intended jump cases. At the same time, head first impact appeared in all homicidal cases, $71.4 \%$ of accidental cases, $50 \%$ of suicidal cases, and $75 \%$ of obscure cases. However, no significant association could be detected between the manner of death and the site of primary impact in the current study. Murthy et al. (2012) concluded that the study of the pattern of injuries might indicate the height from which the fall has occurred and the primary site of impact. Determining the actual or probable anatomical site of primary impact may help in events reconstruction and assessment of death manner (Kumar and Srivatava, 2013).

Poly-trauma was the cause of death in the main bulk of cases, followed by head injuries, then chest and abdomen injuries. A finding supported by Kleber et al. (2012) and Kasim et al. (2018) reported that most traumatic deaths occurred on-scene or during transport to medical care, and the leading cause of death is polytrauma. Furthermore, Ramadan et al. (2016) found that the cause of death in most victims was head injuries in conjunction with abdominal injuries and spinal and thoracic injuries followed by combined abdominal, thoracic, and spinal injuries as well as abdominal and thoracic injuries. In the current study, all the studied cases revealed multiple gross fatal injuries, except for two cases coinciding with ElGohary et al. (2016), who believed that the diagnosis of falling from a height as a cause of death is associated with finding combined multiple sites fatal injuries.

In the current study, toxicological screening was carried out and proved positive for the psychotropic drug in $2.4 \%$ of cases, which might be the cases with a history of psychic problems; no case had a history of drug abuse. Toxicological screening is a critical issue that might help solve the problem of fatal falls from height. Positive toxicological screening for the psychotropic drug could constitute an indirect clue for suicide, even in the absence of a history of psychiatric illness (Türk, 2008). Psychiatric illness may cause addiction to some drugs or abuse substances that might be implicated in intentional, accidental, and homicidal falls 
from height (Pavia et al., 2005). Qualitative and quantitative toxicological analysis significantly contributes to suicide diagnosis by revealing unknown psychiatric treatment or a toxic level (Fanton et al., 2007). Reference-wise, alcohol intake is considered a contributing factor in accidental falls (Murthy et al., 2012).

In falls, the mechanical force that causes injuries is supplied by the movement of the body itself. Counterforce in the first instance is provided by body inertia; in the second instance, it is provided by a stationary object's rigidity against which the body falls. At the moment of impact, the falling body is affected by deceleration forces, and the amount of kinetic energy transferred to the ground is opposed by an equal amount of energy against the body itself. The energy lost is reabsorbed by the person himself in the form of injuries (Chao et al., 2000). External injuries, including abrasions, contusions, and lacerations, were diffusely involving different body regions. External injuries involving the neck region were seen in one case. Hartshorne et al. (1997), together with Kohli and Banerjee (2006), recorded similar types and distribution of external injuries.

Diffuse head injuries involving bones, meninges, and brain and accompanying intracranial hemorrhage were encountered in nearly all cases of this study. Dickinson et al. (2012) found that head injuries significantly increase the likelihood of death. According to Kasim et al. (2018), most injuries are confined to the head, skin, and subcutaneous tissues. $73 \%$ of those who died had head injuries, and $50 \%$ had subarachnoid hemorrhages. In Egypt, Haggag et al., 2016, together with Ramadan et al. (2016), supposed comparable internal autopsy findings, where the head was the most affected and neck was the least affected. Traumatic shock and multiple organ damages like scalp injuries, skull fracture with meningeal hemorrhages, and brain injuries were found.

According to Kohli and Banerjee (2006), different head injuries and accompanying deaths affected most cases. Head injuries were characteristically reported in falls from up to thirty feet height $(9 \mathrm{~m})$ by Li and Smialek, (1994); Turk and Tsokos, (2004) and Atanasijevic et al., (2005). Head injuries accounted for only $27 \%$ of cases in falls from a great height (Hahn et al., 1995). It is unlikely to find a significant head and body injury in a shortfall/ ground level fall (Reiber, 1993).

Skull fractures were distributed amongst vault $(66 \%)$ and base $(40 \%)$ in the present study. This result goes parallel with the results obtained by Kohli and Banerjee (2006). However, it is in sharp contrast to ground level and pedestrians' falls where vault fractures were rare and most of the fractures involved skull base (Ryan et al., 1994; Hartshorne et al., 1997). Brain and meningeal involvement were seen in $78 \%$ and $83 \%$ of cases, respectively. These findings are similar to those of Hartshorne et al. (1997), Goonetilleke (1980), and Kohli and Banerjee (2006).

In this study, upper and/or lower limb injuries were seen in $26 \%$ of cases; cervical vertebrae injuries were encountered in $2 \%$ of cases. Meanwhile, thoracic cage injuries (rib fractures) were reported in 69\% of cases. Such results were consistent with comparable studies that discussed falling from more than 6 meters' height (Kohli and Banerjee, 2006; Haggag et al., 2016; Ramadan et al. 2016; Kasim et al., 2018). However, these results were contradictory to data gathered by authors who include a high incidence of falls from a low height $(\leq 1$ meter), which lead to minor injuries usually in the extremities (Grivna et al., 2014; ElGohary et al. 2016). 
Heart injuries took place in $4.8 \%$ of cases, and thoracic cage injuries (rib fractures) were reported in $69 \%$ of cases. This demonstrates the protective mechanism that the rib cage offers, especially in falls between 10-20 feet (Kohli and Banerjee, 2006). Abdominal organs do not have such defensive cover demonstrated a greater frequency of damage. The liver was the most common organ involved (19\%). Kidneys escaped damage because of their location and small size and were involved in only $7 \%$ of cases. Other authors investigating falls from height exhibited similar results. They concluded an increase in the incidence of internal injuries to the chest and abdomen as the height of falls increased ( $\mathbf{L i}$ and Smialek, 1994; Atanasijevic et al., 2005). In groundlevel falls, chest and abdominal injuries are rare (Hartshorne et al., 1997).

The injuries pattern described in the current study was consistent with most of the literature (Xia et al., 2012; Prathapan and Umadethan, 2015; Rocos et al., 2015; Haggag et al., 2016 and Ramadan et al., 2016) who demonstrated related injuries. Head and thorax were the most affected regions, followed by the abdomen and pelvis, then extremities. The neck was the least affected. Bruno et al. (2014) stated that across all available literature, the strong common denominator for injury pattern is the high prevalence of head, thoracic and abdominal injuries, and the least prevalence of neck injuries. Internal organs like the liver and lung were injured mainly in cases of primary side-impact due to deceleration.

The major limitation of the current study was that the fall height was considered in the records. No site visits were conducted to determine the accurate height of the fall. Furthermore, this study was a time-limited investigation constructed upon information from a single institute (Tanta Department of Forensic Institute). This may not adequately reflect the spectrum of sustained injuries.
Trauma scores were not calculated or declared in the records, so possible predictors of injury severity could not be ascertained. It is essential to highlight that it is not easy to avoid neither of these limitations.

In conclusion, the current study is from a single center to evaluate the pattern of injuries the following fall from a height, according to Tanta Forensic Institute trauma registry. Most of the injuries following fall from height were found to be domestic. The following injury patterns were observed; they are quite different from those of pedestrian injuries or ground-level falls:

- External injuries, including abrasions, contusions, and lacerations, were diffusely involving different body regions except for the neck.

- Skull fractures are distributed evenly amongst vault and base. Nearly all cases showed diffuse head injuries involving bones, meninges, and brain and accompanying intracranial hemorrhage. Polytrauma is the most predominant cause of death. After the brain, thoracic cage and lung injuries were encountered in more than half of the cases. The liver is the most common abdomino-pelvic organ involved.

\section{To be recommended:}

Further studies with a similar design based on data gathered from Forensic Institute worldwide, including larger victims scale, should be done to cover all patterns of injuries and provide a substantial contribution in the analysis of the current results.

A unified protocol designed by Egyptian forensic experts for documentation in fatal fall cases from a height to avoid the deficient aspects of data collection to be applied in the Forensic Institute all over the republic.

Awareness campaigns should be started to people aware of risks involved in the rooftops and safety measures for falls prevention. 
Safety railings and proper lighting should be present on roofs and balconies.

\section{REFERENCES}

Agalar, F.; Cakmakci, M. and Sayek, I. (1999): "Factors effecting mortality in urban vertical free falls: evaluation of 180 cases". Int Surg., 84: 271-274.

Arbes, S. and Berzlanovich, A. (2014): "Injury pattern in correlation with the height of fatal falls". Wiener klinische Wochenschrift..The central European journal of Medicine, 127: 508-514. DOI 10.1007/s00508-014-0639-9

Atanasijevic, T.C.; Popovic, V.M. and Nikolic, S.D. (2009): "Characteristics of chest injury in falls from Heights". Legal Medicine, 11: S315-S317.

Bruno, C. M.; Alessio, B.; Alberto, B.; et al. (2014): "The injury pattern in fatal suicidal falls from a height: An examination of 307 cases". Forensic Science International, 244: 57- 62.

Casali, M. B.; Battistini, A.; Blandino, A. and Cattaneo, C. (2014): "The Injury Pattern in Fatal Suicidal Falls from a Height: An Examination of 307 Cases". Forensic Sci Int., 244: 57- 62

Chao, T. C.; Lau, G. and Teo, C. E. (2000): "Fall from Height: The Pathology of Trauma from Vertical Deceleration". In: Pathology of Trauma, 3rd edition, Mason, J. K. and Purdue, B. N. (editor), Arnold, London. Pp:313- 326. doi: 10.5505/tjtes.2013.77535.

Dickinson, A.; Roberts, M. and Kumar, A.; et al., (2012): "Falls from height: injury and mortality". J $R$ Army Med Corps, 158 (2):123-127.

ElGohary, M. S.; Enas I. Elmadah, E. I. and Wahdan A. A. (2016): "Falling from height:an interesting unusual pattern of injuries". Egypt J. Forensic Sci. Appli. Toxicol 16 (1) :23-35.
Ersoy, S.; Sonmez, B.M; Yilmaz, F.; Kavalci, C.; Ozturk, D. and Altinbilek, E., et al. (2014): "Analysis and Injury Patterns of Walnut Tree Falls in Central Anatolia Of Turkey". World $J$ Emerg Surg., 9:42-46.

Fanton, L.; Bévalot, F. and Schoendorff, P.; et al. (2007): "Toxicological aspects of deaths due to falls from height". The American Journal of Forensic Medicine and Pathology, 28 (3): 262-266.

Gill, J.R. (2001):"Fatal descent from height in New York city", J Forensic Sci., 46 (5):1132-1137.

Goodacre, S.; Than, M.; Goyder, EC; and Joseph, A.P. (1999): "Can the distance fallen predict serious injury after a fall from a height?". J Trauma, (46) 10551058.

Goonetilleke UKDA (1980): "Injuries caused by falls from heights". Med. Sci. Law, 20 (3), 262-75.

Goren, S.; Subasi, M.; Týrasci, Y. and Gurkan, F. (2003): "Fatal falls from heights in and around Diyarbakir, Turkey". Forensic Sci Int., 137: 37-40.

Grivna, M.; Eid, H. O. and Abu-Zidan, F. M. (2014): "Epidemiology, Morbidity and Mortality from Fall-Related Injuries in the United Arab Emirates". Scand J Trauma Resusc Emerg Med, 22: 51-55.

Gulati, D.; Aditya, N. A.; Sudhir, K. and Anil, A. (2012): "Skeletal injuries following unintentional fall from height" Turkish Journal of Trauma \& Emergency Surgery. Original Article. Ulus Travma Acil Cerrahi Derg. Klinik Çalışma, 18 (2):141-146

Gupta, S.M.; Chandra, J. and Dogra, TD. (1982): "Blunt force lesions related to the heights of a fall". Am. J. Forensic Med. Pathol., 3: 35-43. 
Haggag, Q.G.; Zamzam, I. S.; Sharaf Eldin, A. I. and Madboly, A. G. et al. (2016): "Pattern of fatal injuries of fall from height at great cairo: a retrospective analytical study (2009 - 2013)". Egypt J. Forensic Sci. Appli. Toxicol, 16 (2): $97-$ 116.

Hahn, M.P.; Richter, D.; Ostermann, P.A. and Muhr, G. (1995): "Injury pattern after a fall from a great height. An analysis of 101 cases". Unfallchirurg, 98 (12), 609-613.

Hartshorne, N.J.; Harruff, R.C. and Alvard Jr., E.C. (1997): "Fatal head injuries in ground-level falls. Am. J. Forensic Med. Pathol., 18 (3): 258-64.

Holger, M.; Drobnik, S.; Hubig, M. and Sch€onpflug, M.; et al. (2013):"Fall from a Balcony-Accidental or Homicidal? Reconstruction by Numerical Simulation" J Forensic Sci, 58 (4): 1061-1064. doi: 10.1111/15564029.12148

Içer, M.; Güloğlu, C. and Orak, M. et al., (2013): "Factors affecting mortality caused by falls from height. Ulus Travma Acil cerr Derg; 19: (6). 529-535.

Jain, V.; Jain, S. and Dhaon, B.K. (2014): "A multi factorial analysis of the epidemiology of injuries from falls from heights". Int J Crit Illn Inj Sci., 4 (4):283287.

Jamebozorgi, A. A.; Kavoosi, A.; Shafiee, Z.; Kahlaee, A. H. and Raei, M. (2013): "Investigation of the Prevalent Fall Related Risk Factors of Fractures in Elderly Referred to Tehran Hospitals". Med J Islam Repub Iran, 27: 23- 30

Kasim, T.; Mehmet E. S.; Cemil C. and Taner G.; et al. (2018): "Falls from Height: A Retrospective Analysis" World J Emerg Med, 9 (1): 46-50.

Kleber, C.; Giesecke, M.T.; Tsokos, M. and Haas, N.P.; et al. (2012): "Overall distribution of trauma-related deaths in
Berlin 2010: advancement or stagnation of German trauma management?" World J Surg., 36 (9):2125-2130.

Knapp Herschel. (2017) "Introductory Statistics Using SPSS". SAGE Publications, Inc.

Kohli, A. and Banerjee, K.K. (2006): "Pattern of injuries in fatal falls from buildings." Med Sci Law., 46 (4):335341.

Kumar, J.K. and Srivastava, A.K. (2013): "Pattern of Injuries in fall from Height". Journal of Indian Academy Forensic Medicine, 35 (1): 971-973.

Lalwani, S.; Agnihotri, AK; Talreja, A. and Murty, O.P. (1999): "Patterns of injuries in fatal falls from heights A retrospective review". J. Forensic Med. Toxicol. 16 (2): 38-46.

Lapostolle, F.; Gere, C.; Borron, S. W.; Petrovic, T.; et al. (2005): "Prognostic Factors in Victims of Falls from Height". Crit Care Med, 33 (6): 1239- 1242. doi: 10.1097/01.CCM.0000164564.11989.C 3

Li, L. and Smialek, J.E. (1994): "The investigation of fatal falls and jumps from heights in Maryland (1987-1992). Am. J. Forensic Med. Pathol., 15 (4): 295-299.

Mirza, F. H.; Parhyar, H. A.; Tirmizi, S. Z. and Waheed, A. (2013): "Fatalities of Fall Injuries in Karachi-a Five Year Autopsy Based Study". Medical Chanel, 19: 53- 58.

Murthy, V.C.; Harish, S. and Chandra, Y.G. (2012): "The Study of Pattern of Injuries in Fatal Cases of fall from Height". Al Ameen Journal of Medical Sciences, 35 (1):47-51.

Osifo, O. D.; Iribhogbe, P. and IdiodiThomas, H. (2010): "Falls from Heights: Epidemiology and Pattern of Injury at the Accident and Emergency Centre of the University of Benin Teaching Hospital". Injury, 41: 544- 547 
Pavia, M.; Nicotera, G. and Scaramuzza, G.; et al. (2005): "Suicide mortality in Southern Italy: 1998- 2002". Psychiatry Research, 134 (3): 275-279.

Petaros, A.; Slaus, M.; Coklo, M.; Sosa, I. and Cengija, M. (2013):"Retrospective Analysis of Free Fall Fracture with Regard to Height and cause of fall ". Forensic Science International, 226 (1): 290-295.

Prathapan, V. and Umadethan, B. (2015):"Fall from heights-patterns of injuries". International Journal of Biomedical Research, (6) (01):8-13.

Ramadan, M. M.; Elsayed, A. A.; Mahmoud, N. A. and Allam, A. M. (2016): "Pitfalls Encountered during Documentation of Cases of Fatal Fall from Height Presented to Kafr EL Sheikh-Medicolegal Department during the Period from (1999 to 2013)" Ain Shams Journal of Forensic Medicine and Clinical Toxicology, 27: 105- 116.

Reiber, G.D. (1993): "Fatal falls in childhood. How far must children fall to sustain fatal head injury? Report of cases and review of literature. Am. J. Forensic Med. Pathol., 14 (3): 201-7.

Rocos, B.; Acharya, M. and Chesser, T.J.S. (2015): "The Pattern of Injury and
Workload Associated with Managing Patients After Suicide Attempt by Jumping from a Height". The Open Orthopaedics Journal, 9:395-398.

Ryan, G.A.; Mclean, A.J.; Vilenium, A.T.S. and Kloeden, C.N.; et al. (1994): "Brain injury patterns in fatally injured Pedestrians". J. Trauma. 36 (4): 469-476.

Thierauf, A.; Preuss, J.; Lignitz, E. and Madea, B. (2010): "Retrospective Analysis of Fatal Falls". Forensic Sci Int, 189: 92-96.

Törő, K.; Szlávik, N. and Mészáros, A. et al. (2006): "Jumping and falling death in children, adolescents, and young adults". Journal of Clinical Forensic Medicine, 13 (3): 129-134.

Türk, E.E. (2008): Fatal falls from height. In Forensic pathology review volume (5) part II, Trauma. Tsokos M (Ed), Humana Press. Page 25-39.

WHO (2012): "Fact Sheet N³44". http://www.who.int/mediacentre/factshe ets/fs344/en/

Xia, P.; Chang, H. and Yu, Y. et al., (2012): "Morphologic studies of high fall injuries". Chinese Journal of Traumatology, 15 (6): 334-337. 


\section{الملخص العربي}

\section{الأنماط الاصابيه فى حالات السقوط المميت من علو بمحافظة الغربية: دراسة تثريحية}

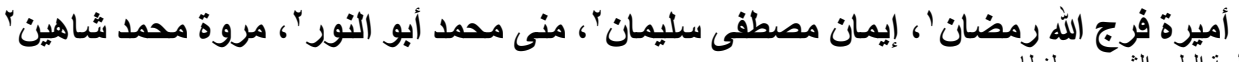

$$
\begin{aligned}
& \text { ( مصلحة الطب الثرعي بطنطا }
\end{aligned}
$$

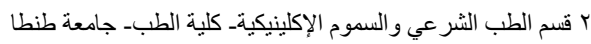

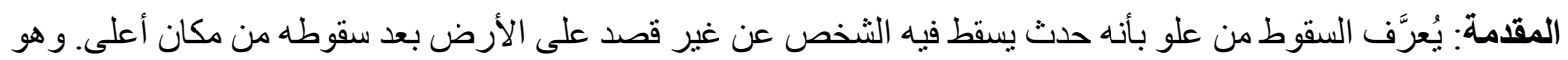

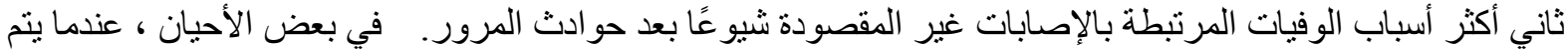

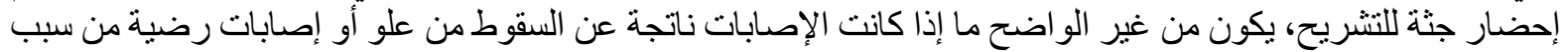

الهـف من الدراسة: الهدف من هذه الدراسة هو تسليط الضو ء على الإصابات في حالات السقوط المميتة من علو بحيث

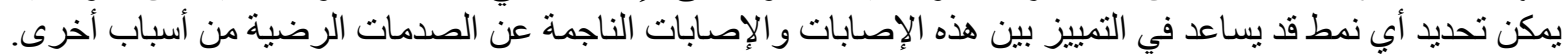

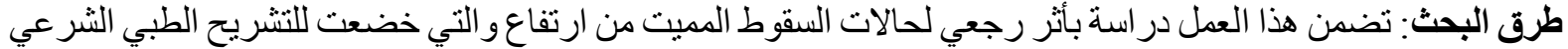

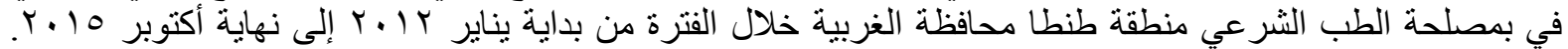

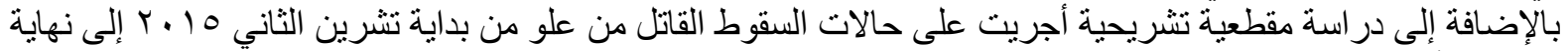

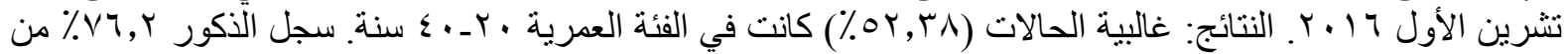

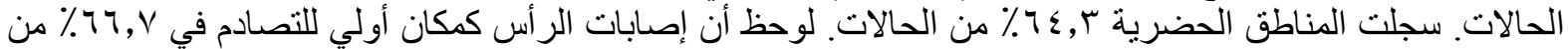

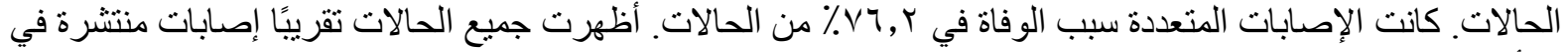

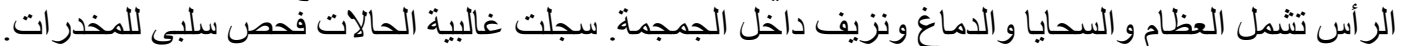

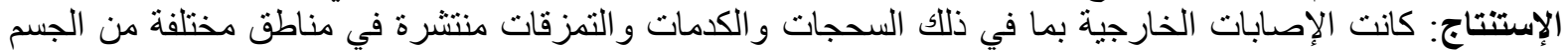

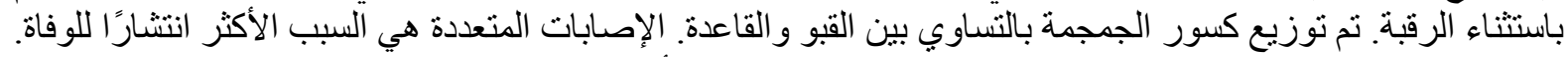

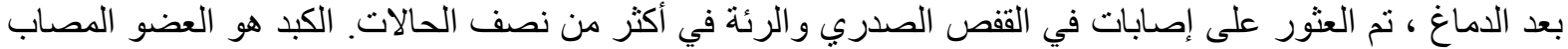

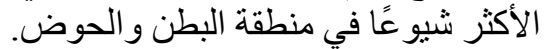

الكلمات الرئيسية: السقوط من علو، الإصابات المتعددة، التصادم الأول، مصلحة الطب الثرعي، إصابات الر أس. 